\title{
Onset age is a risk factor for refractory pediatric IgA vasculitis: a retrospective cohort study
}

\author{
Chun-Hua Liao', Melody Tsai ${ }^{1}$, Yao-Hsu Yang ${ }^{1}$, Bor-Luen Chiang ${ }^{1,2}$ and Li-Chieh Wang ${ }^{1 *}$ (D)
}

\begin{abstract}
Background: Though outcome differences between children and adults with immunoglobulin A vasculitis (IgAV) has been well documented, it remains unclear if disease features in pediatric IgAV patients vary with onset age. We aimed to explore clinical features and prognosis of pediatric IgAV stratified by onset age.

Methods: We retrospectively reviewed records of patients under 18 years old diagnosed with IgAV from January 1999 to December 2018 in one tertiary medical center in Taiwan. Patients were grouped by onset age: $\leq 6$ years old, $6-12$ years old $(>6, \leq 12)$, and $12-18$ years old $(>12,<18)$. Demographics, laboratory data, incidence of gastrointestinal, renal, and joint involvement, corticosteroid dependence, recurrence, and refractory disease were analyzed. Recurrence was defined as disease flare-up after complete remission and discontinuation of all medications for at least 3 months. Corticosteroid dependence was defined by more than 6 weeks of daily oral corticosteroid intake. Refractory disease was defined as not achieving complete remission 6 months after disease onset. Statistical analysis was performed using R software (v3.6.0).
\end{abstract}

Results: There were 484 IgAV patients, with an onset age of 6.10 (4.72-8.58) (median (IQR)) years old. There were $234(48.3 \%)$ patients $\leq 6$ years old, 210 (43.4\%) 6-12 years old, and 40 (8.3\%) 12-18 years old. One hundred and thirty (26.9\%) patients had renal involvement, which was more frequent in older children ( $\leq 6$ years old, $18.4 \%$; 6 12 years old, 31.0\%; 12-18 years old, 55.0\%; $p<0.001)$. There were 361 patients (74.6\%) with joint involvement; younger children were affected more frequently ( $\leq 6$ years old, $82.1 \%$; $6-12$ years old, $71.9 \% ; 12-18$ years old, $45.0 \%$; $p<0.001)$. Gastrointestinal involvement was present in 311 (64.3\%) patients, showing no difference among age groups. There were 46 patients (9.5\%) with recurrent IgA vasculitis, 136 (28.1\%) with corticosteroid dependent and 76 (15.7\%) with refractory disease. Corticosteroid dependence and refractory disease occurred more frequently as onset age increased $(p<0.001)$.

Conclusion: Pediatric IgAV with different onset ages are associated with distinct clinical manifestations and outcomes. The risk of developing corticosteroid dependence, refractory disease and renal involvement increased with onset age.

Keywords: Pediatric IgA vasculitis, Onset age, Corticosteroid dependence, Refractory, Renal involvement

\footnotetext{
*Correspondence: Icwang5@ntu.edu.tw

'Department of Pediatrics, National Taiwan University Hospital, No.8, Chung Shan South Road, Taipei 10002, Taiwan

Full list of author information is available at the end of the article
} 


\section{Background}

Immunoglobulin A vasculitis (IgAV), also known as Henoch-Schönlein purpura, is the most common vasculitis in children, with an annual incidence of 13-20 per 100,000 children, and a peak age of onset between 4 to 6 years old [1-3]. The male to female ratio is around 1.1 $[2,3]$. Though the exact pathogenic mechanisms remain unclear, previous studies suggested that IgAV might be associated with infection, supported by observations of seasonality and preceding upper airway infections [4].

The pathological hallmarks in IgAV are deposition of immunoglobulin A (IgA) at the walls of small vessels and perivascular neutrophil infiltration. In previous in vitro studies, IgA anti-endothelial cell antibodies from IgAV patients activated endothelial cells to produce cytokines such as interleukin-8 (IL-8), and further resulted in inflammatory responses and neutrophil migration [5]. These findings suggest that the interaction between $\operatorname{IgA}$, neutrophils, and endothelial cells might play a major role in the pathogenesis of IgAV [6].

Typical symptoms and signs of IgAV include nonblanchable purpura (mostly over the lower extremities), arthralgia/arthritis, abdominal cramping pain, and hematuria/proteinuria. Though its prognosis is considered benign in children, adults with IgAV have a higher risk of developing refractory renal, gastrointestinal (GI), and neurological disease. Compared to children, adults with IgAV have distinct epidemiology and disease manifestations. The annual incidence is lower, around 0.34 to 1.4 per 100,000 persons [7], and the male to female ratio is higher, up to 1.5 [8]. There is a higher frequency of renal involvement, around 50-85\% [9-12], a higher risk of progression to renal insufficiency, and increased mortality of all causes [13].

While outcome differences between children and adults with IgAV have been well documented, it is less clear whether and how disease features in pediatric IgAV patients vary with onset age. We aimed to clarify the differences between children of different age groups in terms of disease presentation and prognosis.

\section{Methods}

We retrospectively reviewed the medical records of the patients under 18 years old with a diagnosis of IgAV from January 1999 to December 2018 at one tertiary medical center in Taiwan. The diagnosis of IgAV was based on validated criteria defined by the 2010 European League Against Rheumatism/Pediatric Rheumatology International Trials Organization/Pediatric Rheumatology European Society (EULAR/PRINTO/PRES) [14]. Patients were divided into three groups according to onset age: $\leq 6$ years old, $6-12$ years old $(>6, \leq 12)$, and $12-18$ years old $(>12,<18)$. We retrieved epidemiologic characteristics, laboratory data at onset, organ involvement, prescribed medications, including: corticosteroids (CS), non-steroidal anti-inflammatory drugs (NSAIDs), and disease-modifying anti-rheumatic drugs (DMARDs), total CS exposure duration, total CS cumulative dose, exposure duration of high dose CS (equivalent dose of oral prednisolone $\geq 1 \mathrm{mg} / \mathrm{kg} /$ day), recurrence rate, CS dependent rate, and refractory rate.

\section{Definition of renal involvement}

Renal involvement was defined as hematuria and/or proteinuria. Hematuria was defined by the presence of at least five red blood cells (RBCs) per high power field or $\mathrm{RBC} \geq 2+$ on dipstick or $\mathrm{RBC}$ casts in the urinary sediment. Proteinuria was defined as protein loss of more than $0.3 \mathrm{~g}$ per $24 \mathrm{~h}$ or $>30 \mathrm{mmol} / \mathrm{mg}$ of urine albumin to creatinine ratio on a spot morning sample.

\section{Definition of recurrent $\lg A V$, refractory $\lg A V$, and CS dependence}

Recurrent IgAV was defined as disease flare-up after complete remission and discontinuation of all medications for at least 3 months. CS dependence was defined by more than 6 weeks of daily oral CS intake. Refractory disease was defined as not achieving complete remission 6 months after disease onset. Complete remission was defined as the resolution of skin purpura, arthralgia/ arthritis, and abdominal pain, combined with normal renal function and absence of proteinuria and hematuria, as well as discontinuation of all medication.

\section{Statistical analysis}

Laboratory data were presented as median (interquartile range, IQR). Continuous data were compared using the Kruskal-Wallis test. We compared categorical variables and proportions by using the chi-square test. Univariate and multivariate regression models were used to identify significant factors associated with clinical outcomes. To model the relationship between outcome probabilities and onset age, allowing for nonlinear effects, we used logistic regression with restricted cubic spline basis functions, with four evenly spaced knots [15]. We also tested modeling with three to six knots, which yielded highly similar results. The optimal threshold in receiver operating characteristic (ROC) curve analysis was chosen by maximizing Youden's index. A threshold of $P<0.05$ was used for statistical significance. Statistical analyses were conducted with $\mathrm{R}$ software (version 3.6.0), using the rms, pROC, and cutpointr packages. The ggplot 2 package was used for visualizations.

\section{Results}

Patient characteristics

There were 484 patients enrolled in this retrospective study. Demographic data and clinical characteristics of 
all patients and the three subgroups are summarized in Table 1 . There were 252 boys among all patients, and the male to female ratio was 1.09. The onset age was 6.10 (IQR:4.72-8.58) years old. Among all patients, $234(48.3 \%)$ patients were $\leq 6$ years old; 210 (43.4\%) of them were $6-12$ years old, and 40 (8.3\%) were $12-18$ years old. The percentage of male patients showed no significant difference among the three subgroups. Overall, preceding infection symptoms and/or signs were noted in $304(62.8 \%)$ patients, but they occurred more frequently in younger age groups $(\leq 6$ years old, $71.8 \%$; $6-12$ years old, $56.2 \%$; $12-18$ years old, $40.0 \% ; P<0.001)$. More than half of the cases occurred in autumn and winter, though without statistical significance. $(P=0.670$, data not shown, see Additional file 1: Table S1).

Renal involvement was noted in 130 (26.9\%) patients, and it occurred more frequently in older children ( $\leq 6$ years old, $18.4 \%$; $6-12$ years old, $31.0 \%$; 12-18 years old, $55.0 \% ; P<0.001)$. Three hundred sixty-one patients $(74.6 \%)$ had arthritis or arthralgia, and it was found more frequently in younger children ( $\leq 6$ years old, $82.1 \%$; $6-12$ years old, $71.9 \% ; 12-18$ years old, 45.0\%; $\mathrm{P}<0.001)$. GI involvement was noted in $311(64.3 \%)$ of the patients. There was no difference in the incidence of GI associated symptoms among the subgroups.

\section{Laboratory analysis}

Hemoglobin (Hb), platelet (Plt), white blood cell count (WBC), neutrophil count, lymphocyte count, neutrophil to lymphocyte ratio (NLR), platelet to lymphocyte ratio (PLR), and serum IgA were compared among the three subgroups via Kruskal-Wallis test; the results are summarized in Table 2. Hb, lymphocyte count, NLR, PLR, and IgA showed significant differences among the three subgroups. Because normal values of hemoglobin, WBC, neutrophil count, lymphocyte count and level of $\operatorname{IgA}$ varied across different ages, we used age-corrected Zscores to offset the possible age effect $[16,17]$. After adjustment by age, the Z-score for lymphocyte count showed no significant difference over different age subgroups. As onset age increased, the Z-score of WBC increased, but the Z-scores of $\mathrm{Hb}$ and IgA declined significantly (Table 3 ). We did not adjust NLR and PLR by age, because there was no validated normal range for NLR and PLR of different ages.

\section{Medication}

The most commonly used medications were NSAIDs and CS, which were prescribed to 90.1 and $83.9 \%$ of the patients, respectively. Azathioprine (46.3\%) was the most commonly prescribed DMARD, followed by cyclosporine (13.2\%) and hydroxychloroquine (12.6\%).

Table 1 Demographic and clinical manifestations in pediatric IgA vasculitis according to different onset ages

\begin{tabular}{|c|c|c|c|c|c|}
\hline & Total $(n=484)$ & $\leq 6 Y(n=234)$ & $6-12 Y(n=210)$ & $12-18 Y^{a}(n=40)$ & $P$ value \\
\hline Onset age, years old & $6.10(4.72-8.58)$ & $4.68(3.83-5.27)$ & $7.91(6.88-9.55)$ & $14.48(12.97-15.90)$ & \\
\hline Male sex & $252(52.1 \%)$ & $122(52.1 \%)$ & $110(52.4 \%)$ & $20(50.0 \%)$ & 0.962 \\
\hline Preceding infection & $304(62.8 \%)$ & $168(71.8 \%)$ & $118(56.2 \%)$ & $16(40.0 \%)$ & $<0.001$ \\
\hline \multicolumn{6}{|l|}{ Manifestation } \\
\hline Skin purpura & $484(100 \%)$ & $234(100 \%)$ & $210(100 \%)$ & $40(100 \%)$ & NA \\
\hline Arthralgia/arthritis & $361(74.6 \%)$ & $192(82.1 \%)$ & $151(71.9 \%)$ & $18(45.0 \%)$ & $<0.001$ \\
\hline CNS/PNS involvement & $5(1.0 \%)$ & $2(0.9 \%)$ & $2(1.0 \%)$ & $1(2.5 \%)$ & NA \\
\hline Gl involvement & $311(64.3 \%)$ & $156(66.7 \%)$ & $130(61.9 \%)$ & $25(62.5 \%)$ & 0.562 \\
\hline Abdominal pain & $294(60.7 \%)$ & $147(62.8 \%)$ & $123(58.6 \%)$ & $24(60.0 \%)$ & 0.654 \\
\hline Vomiting & $100(20.7 \%)$ & $50(21.4 \%)$ & $44(21.0 \%)$ & $6(15.0 \%)$ & 0.649 \\
\hline Diarrhea & $34(7.0 \%)$ & $11(4.7 \%)$ & $18(8.6 \%)$ & $5(12.5 \%)$ & 0.103 \\
\hline Gl bleeding & $42(8.7 \%)$ & $23(9.8 \%)$ & $15(7.1 \%)$ & $4(10.0 \%)$ & 0.576 \\
\hline Positive stool occult blood & $111(22.9 \%)$ & $56(23.9 \%)$ & $44(21.0 \%)$ & $11(27.5 \%)$ & 0.586 \\
\hline Renal involvement & $130(26.9 \%)$ & $43(18.4 \%)$ & $65(31.0 \%)$ & $22(55.0 \%)$ & $<0.001$ \\
\hline Microscopic hematuria & $129(26.7 \%)$ & $43(18.5 \%)$ & $64(30.5 \%)$ & $22(55.0 \%)$ & $<0.001$ \\
\hline Gross hematuria & $10(20.7 \%)$ & $4(1.7 \%)$ & $6(2.9 \%)$ & 0 & NA \\
\hline Non-nephrotic proteinuria & $24(5.0 \%)$ & $8(3.4 \%)$ & $13(6.2 \%)$ & $3(7.5 \%)$ & 0.301 \\
\hline Nephrotic syndrome & $8(1.7 \%)$ & $2(0.9 \%)$ & $5(2.4 \%)$ & $1(2.5 \%)$ & NA \\
\hline
\end{tabular}

Data shown are median (IQR) or number (\%) of patients as appropriate

Abbreviations: IgA Immunoglobulin A, CNS Central nervous system, PNS Peripheral nervous system, GI Gastrointestinal, NA Not available

a Patients were grouped by onset age: $\leq 6 \mathrm{Y}$ (years old), 6-12 Y ( $>6, \leq 12$ years old), and $12-18 \mathrm{Y}(>12,<18$ years old) 
Table $\mathbf{2}$ Laboratory parameters in pediatric IgA vasculitis patients in different onset age groups

\begin{tabular}{|c|c|c|c|c|}
\hline & $\leq 6 Y(n=234)$ & $6-12 Y(n=210)$ & $12-18 Y^{a}(n=40)$ & $P$ value \\
\hline $\mathrm{Hb}(\mathrm{g} / \mathrm{dl})$ & $12.60(11.9-13.3)(n=178)$ & $13.10(12.30-13.70)(n=161)$ & $13.55(12.95-14.40)(n=24)$ & $<0.001$ \\
\hline Plt $\left(10^{9} / \mathrm{L}\right)$ & $346.0(284.0-427.0)(n=178)$ & $345.0(300.0-406.0)(n=161)$ & $345.5(260.8-389.8(n=24)$ & 0.309 \\
\hline $\operatorname{WBC}\left(10^{9} / \mathrm{L}\right)$ & $10,600(8622-12,950)(n=180)$ & $10,615(8478-13,365)(n=158)$ & $9900(8358-11,545)(n=24)$ & 0.609 \\
\hline Neutrophil $\left(10^{9} / \mathrm{L}\right)$ & $6250(4593-8177)(n=177)$ & $7166(5115-10,156)(n=151)$ & $6171(5229-8103)(n=24)$ & 0.049 \\
\hline Lymphocyte $\left(10^{9} / \mathrm{L}\right)$ & $3211.5(2460-4147.1)(n=177)$ & $2598.7(1879.5-3348.9)(n=150)$ & $2195(1645-2872)(n=24)$ & $<0.001$ \\
\hline NLR & $1.91(1.26-2.82)(n=177)$ & $2.95(1.60-4.61)(n=150)$ & $2.68(1.90-4.68)(n=24)$ & $<0.001$ \\
\hline PLR & $\begin{array}{l}108.59(80.38-141.61) \\
(n=175)\end{array}$ & $126.89(100.71-190.99)(n=150)$ & $154.00(106.67-183.42)(n=24)$ & $<0.001$ \\
\hline $\lg \mathrm{A}(\mathrm{mg} / \mathrm{dL})$ & $189.5(137.8-259.0)(n=168)$ & $253.5(217.0-340.5)(n=154)$ & $308.5(231.0-395.8)(n=30)$ & $<0.001$ \\
\hline ANA $\geqq 1: 80$ positive & $12 / 154$ & $14 / 143$ & $2 / 30$ & 0.767 \\
\hline $\mathrm{CRP} \geqq 1 \mathrm{mg} / \mathrm{dL}$ & $63 / 151$ & $42 / 120$ & $12 / 19$ & 0.059 \\
\hline
\end{tabular}

Data are presented as median (IQR)

Abbreviations: Hb Hemoglobin, PIt Platelet, WBC White blood cells, PLR Platelet-to-lymphocyte ratio, NLR Neutrophil-to-lymphocyte ratio, IgA Immunoglobulin A, ANA Antinuclear antibody, CRP C-reactive protein

${ }^{a}$ Patients were grouped by onset age: $\leq 6 \mathrm{Y}$ (years old), 6-12 $\mathrm{Y}(>6, \leq 12$ years old), and $12-18 \mathrm{Y}(>12,<18$ years old)

Twenty patients received methylprednisolone minipulse or pulse therapy $(15 \mathrm{mg} / \mathrm{kg} /$ day for 2 days, with a maximum of $500 \mathrm{mg} /$ day; or $30 \mathrm{mg} / \mathrm{kg} /$ day for 3 days, with a maximum of $1000 \mathrm{mg} /$ day). Three patients received intravenous immunoglobulin $(1 \mathrm{~g} / \mathrm{kg} /$ day for 2 days); two patients received cyclophosphamide pulse therapy for nephrotic syndrome; one patient received rituximab for refractory abdominal pain and arthralgia.

The administrative rate of NSAIDs and CS among the three subgroups showed no significant difference. However, use of DMARDs was more frequent in children over 6 years old ( $\leq 6$ years old, $36.4 \% ; 6-12$ years old, $60.9 \%$; $12-18$ years old, $71.4 \% ; P<0.001$ ) (Table 4 ).

Meanwhile, the cumulative CS dose (body weight adjusted equivalent dose of oral prednisolone) was significantly higher in the 12-18 years old group (median: $22.80 \mathrm{mg} / \mathrm{kg}$, IQR: $13.05-52.65)$ compared with patients $\leq 6$ years old (median: $13.83 \mathrm{mg} / \mathrm{kg}$, IQR: $3.89-29.17$ ) (Fig. 1a) $(P=0.011)$. The total CS exposure duration was also significantly longer in the $12-18$ years old group ( $\leq$ 6 years old, median: 14 days, IQR: $5-32 ; 6-12$ years old, median: 23 days, IQR: $9-52.8 ; 12-18$ years old, median: 62 days, IQR: $25-156.5 ; P<0.001$ ), but the number of days under high dose exposure showed no difference $(P=0.681)$ (Fig. $1 \mathrm{~b}$ and $\mathrm{c})$.

To investigate clinical predictors of DMARD use, we regrouped the patients into three groups: no DMARDs required, DMARDs required, and DMARDs dependent. There were 253 (52.3\%) patients who required DMAR Ds, and 76 of them were DMARDs dependent. Patients with older onset age, gastrointestinal involvement, and renal involvement had higher odds of requiring DMAR Ds; meanwhile, patients with older onset age and renal involvement were more prone to be DMARDs dependent (see Additional file 1: Table S2-S5).

Medication-associated major adverse effects occurred in some patients under azathioprine and cyclosporine. Neutropenia was observed in three cases $(1.3 \%)$ and pancytopenia in two cases $(0.9 \%)$ under azathioprine. Three (4.7\%) patients with renal involvement developed hypertension under the combination of cyclosporine and CS. Apart from CS and/or cyclosporine, the disease process itself could have contributed to the development of hypertension, as underlying inflammatory renal disease has been associated with hypertension [18]. Gum swelling was documented in one (1.7\%) patient taking cyclosporine.

Table 3 Adjusted laboratory parameters in pediatric IgA vasculitis patients in different onset age groups

\begin{tabular}{lllll}
\hline & $\leq \mathbf{6} \mathbf{Y}(\boldsymbol{n}=\mathbf{2 3 4})$ & $\mathbf{6 - 1 2} \mathbf{Y}(\boldsymbol{n}=\mathbf{2 1 0})$ & $\mathbf{1 2 - 1 8} \mathbf{Y}^{\mathbf{a}}(\boldsymbol{n}=\mathbf{4 0})$ & $\mathbf{P}$ value \\
\hline Hb Z score & $0.12 \pm 2.11(n=178)$ & $-0.45 \pm 1.07(n=161)$ & $-0.75 \pm 1.70(n=24)$ & $\mathbf{0 . 0 0 2}$ \\
WBC Z score & $1.77 \pm 1.53(n=180)$ & $2.53 \pm 2.32(n=158)$ & $3.15 \pm 2.51(n=24)$ & $1.88 \pm 2.16(n=24)$ \\
Neutrophil Z score & $1.76 \pm 1.85(n=177)$ & $2.30 \pm 2.80(n=151)$ & $0.16 \pm 1.04(n=24)$ & 0.501 \\
Lymphocyte Z score & $-0.17 \pm 1.08(n=177)$ & $0.07 \pm 1.67(n=150)$ & $2.56 \pm 1.70(n=30)$ & 0.359 \\
IgA Z score & $4.36 \pm 3.74(n=168)$ & $3.10 \pm 1.96(n=154)$ & $\mathbf{0 . 0 0 4}$ \\
\hline
\end{tabular}

Data are presented as mean \pm SD

Abbreviations: Hb Hemoglobin, WBC White blood cells, IgA Immunoglobulin A

${ }^{a}$ Patients were grouped by onset age: $\leq 6 \mathrm{Y}$ (years old), 6-12 Y ( $>6, \leq 12$ years old), and $12-18 \mathrm{Y}(>12,<18$ years old) 
Table 4 Medication use in pediatric lgA vasculitis patients of different onset age

\begin{tabular}{|c|c|c|c|c|c|}
\hline & Total $(n=484)$ & $\leq 6 Y(n=234)$ & $6-12 Y(n=210)$ & $12-18 Y^{\mathrm{a}}(n=40)$ & $P$ value \\
\hline CS & $406(83.9 \%)$ & $193(82.5 \%)$ & $179(85.2 \%)$ & $34(85.0 \%)$ & 0.718 \\
\hline NSAIDs & $436(90.1 \%)$ & $216(92.3 \%)$ & $188(89.5 \%)$ & $32(80.0 \%)$ & 0.518 \\
\hline DMARDs & $253(52.3 \%)$ & 91 (38.9\%) & $133(63.3 \%)$ & 29 (72.5\%) & $<0.001$ \\
\hline Azathioprine & $224(46.3 \%)$ & $83(35.5 \%)$ & $119(56.7 \%)$ & $22(55.0 \%)$ & $<0.001$ \\
\hline Cyclosporine & 64 (13.2\%) & $20(8.5 \%)$ & $33(15.7 \%)$ & $11(27.5 \%)$ & 0.002 \\
\hline hydroxychloroquine & $61(12.6 \%)$ & $22(9.4 \%)$ & 29 (13.8\%) & $10(25.0 \%)$ & 0.018 \\
\hline Others $^{b}$ & $32(6.6 \%)$ & $3(1.3 \%)$ & 18 (8.6\%) & $11(27.5 \%)$ & $<0.001$ \\
\hline
\end{tabular}

Data shown are number (\%) of patients

Abbreviations: IgA Immunoglobulin A, CS Corticosteroid, NSAIDs Non-steroidal anti-inflammatory drugs, DMARDs Disease-modifying anti-rheumatic drugs

a Patients were grouped by onset age: $\leq 6 \mathrm{Y}$ (years old), 6-12 Y ( $>6, \leq 12$ years old), and 12-18 $\mathrm{Y}(>12,<18$ years old)

${ }^{\mathrm{b}}$ Other DMARDs included mesalazine, sulfasalazine, dapsone, colchicine, methotrexate, and mycophenolate mofetil

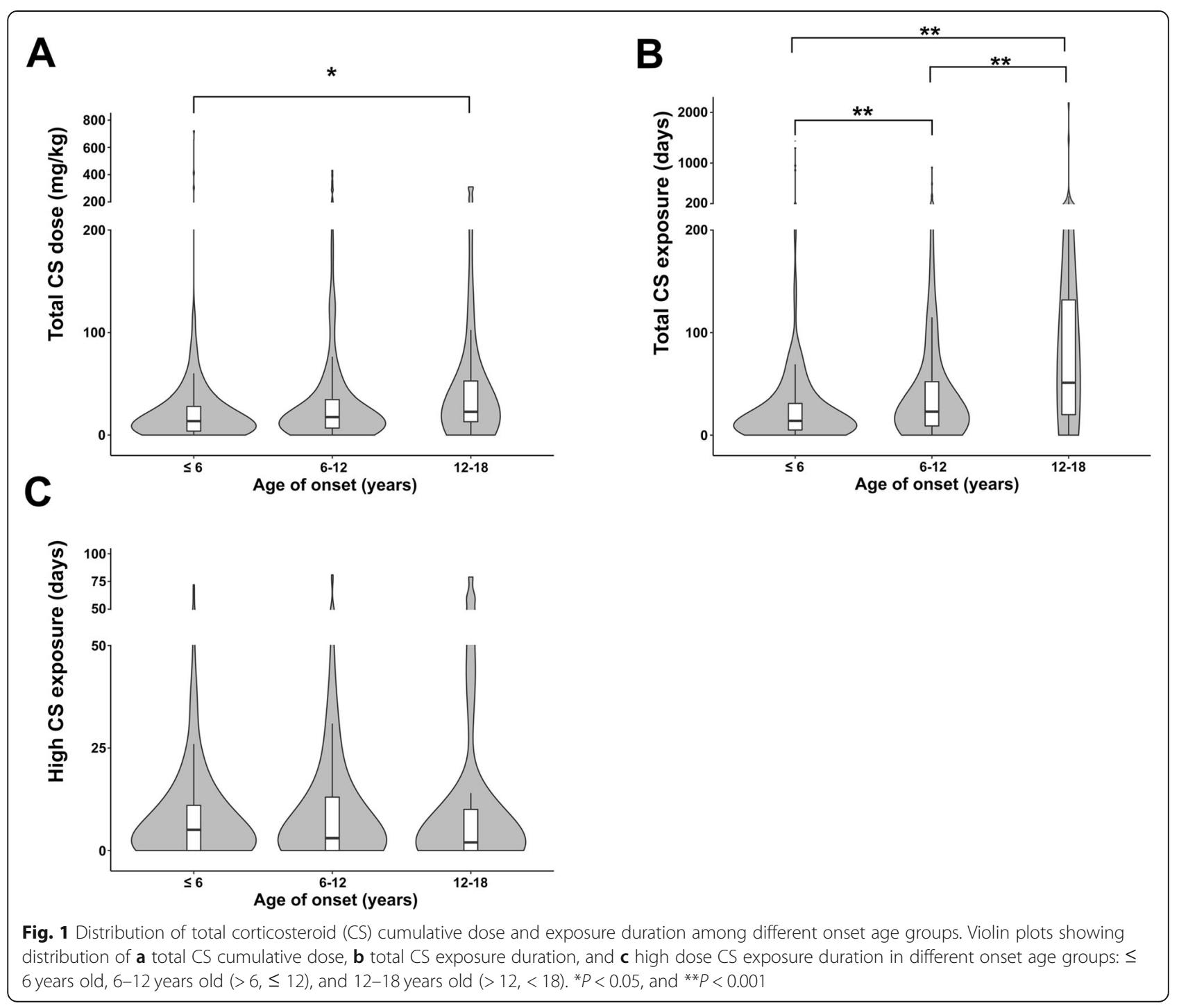


Recurrence, CS dependence, and refractory disease

The overall recurrence rate of IgAV was $9.5 \%$, and recurrence was more frequent in patients older than 6 years old ( $\leq 6$ years old, $7.3 \%$; $6-12$ years old, $9.5 \%$; $12-$ 18 years old, 22.5\%; $P=0.0017)$. CS dependence was defined as CS exposure for more than 6 weeks in any IgAV episode. The CS dependence rate in 12-18 years old $(55.0 \%)$ was significantly higher than the other two groups ( $\leq 6$ years old, $19.2 \%$; $6-12$ years old, $32.9 \%$; $P<$ $0.001)$. The refractory rate showed similar patterns $(\leq 6$ years old, $7.3 \%$; $6-12$ years old, $17.6 \% ; 12-18$ years old, $55.0 \% ; P<0.001)$ (Table 5).

To further determine the major factors in recurrence, refractory disease and CS dependence, we performed univariate logistic regressions. Significant factors by univariate analysis were then entered into multivariate logistic regressions. By multivariate analysis, renal involvement was associated with a 3.05 -fold $(95 \% \mathrm{CI}$, 1.42-6.49; $P=0.004$ ) increased odds of IgAV recurrence, a 20.51-fold (95\% CI, 10.73-41.84; $P<0.001$ ) increased odds of refractory disease, and a 5.46-fold (95\% CI, 2.96-10.22; $P<0.001)$ increased odds of developing CS dependence compared to those without renal involvement (see Additional file 1: Table S6-S8).

Meanwhile, an increase of onset age by 1 year was associated with a 1.27 -fold (95\% CI, 1.16-1.39; $\mathrm{P}<$ 0.001 ) increased odds in developing refractory disease and a 1.12 -fold $(95 \% \mathrm{CI}, 1.03-1.24 ; P=0.012)$ increased odds of being CS dependent (see Additional file 1: Table S7, S8).

To explore whether the risk of developing CS dependence and refractory disease increased linearly with onset age, we modeled the relationship between onset age and these outcomes with restricted cubic spline models. Figure 2 presents the fitted models for the probability of CS dependence and refractory disease at different onset ages. We found that the slope of the curve for CS dependence seemed to become steeper near 6.5 years old (Fig. 2a). At the optimal threshold established by ROC curve analysis (onset age $\geq 6.5$ years old), the sensitivity of onset age to predict CS dependence was $62.5 \%$, and the specificity was $62.6 \%$, with an AUC of 0.64 (Fig. 2c).
The slope of the probability of refractory disease appeared to change near 7.5 years old (Fig. 2b). At the optimal threshold determined by ROC curve analysis (age $\geq 7.2$ years old), the sensitivity of onset age to predict refractory disease was $69.7 \%$, and the specificity was $70.1 \%$, with an AUC of 0.73 (Fig. 2d).

\section{Discussion}

To our knowledge, this is the largest study to demonstrate a distinct clinical course and outcome in children with IgAV of different onset ages. We showed that as onset age increased, patients had arthralgia or arthritis less frequently, but were more prone to renal involvement. Meanwhile, the risk of developing CS dependence increased with onset age, especially in patients older than 6.5 years old. A similar pattern was observed in risk of refractory disease, with a cut point of 7.2 years old. Patients with renal involvement had a higher risk of disease recurrence, but onset age did not impact the recurrence rate significantly.

In IgAV, severe GI involvement, such as massive GI bleeding and intussusception, might lead to mortality. In our series, $64.3 \%$ of patients had GI involvement, while $13.5 \%$ of them presented with GI bleeding. There was no significant difference of GI involvement rate in different age subgroups. In a previous study conducted in Taiwan from 1991 to 2001, the incidence of GI involvement and GI bleeding were 58 and $17.6 \%$, respectively [19], which was similar to our data. The study also identified three cases with severe GI complications (one with intussusception, one with GI perforation, and one with massive GI bleeding induced hypovolemic shock); however, none of these complications were observed in our study. This might be attributed to increased awareness of IgAV complications and prompt treatment. Alternatively, it could echo the observation that clinical features of IgAV demonstrated a trend of progressively less severe phenotypes over the past three decades in Korea [20].

Renal involvement was noted in $25-56 \%$ of pediatric patients with IgAV $[8,12]$. In our study, renal involvement developed in $26.9 \%$ of patients, and it occurred more frequently as onset age increased. Previous studies

Table 5 Recurrence rate, corticosteroid dependence rate, and refractory disease rate in pediatric lgA vasculitis patients of different onset age

\begin{tabular}{llllll}
\hline & Total $(\boldsymbol{n}=\mathbf{4 8 4})$ & $\leq \mathbf{6}$ Y $(\boldsymbol{n}=\mathbf{2 3 4 )}$ & $\mathbf{6 - 1 2}$ Y $(\boldsymbol{n}=\mathbf{2 1 0})$ & $\mathbf{1 2 - 1 8} \mathbf{Y}^{\mathbf{a}}(\boldsymbol{n}=\mathbf{4 0})$ & $\mathbf{P}$ value \\
\hline Recurrence $^{\mathrm{b}}$ rate & $46(9.5 \%)$ & $17(7.3 \%)$ & $20(9.5 \%)$ & $9(22.5 \%)$ & $\mathbf{0 . 0 1 0}$ \\
CS dependence $^{c}$ rate & $136(28.1 \%)$ & $45(19.2 \%)$ & $69(32.9 \%)$ & $22(55.0 \%)$ & $<2(55.0 \%)$ \\
Refractory disease $^{\mathrm{d}}$ rate & $76(15.7 \%)$ & $17(7.3 \%)$ & $37(17.6 \%)$ & $\mathbf{0 . 0 0 1}$ \\
\hline
\end{tabular}

Data shown are number (\%) of patients

Abbreviations: CS Corticosteroid

${ }^{\text {a }}$ Patients were grouped by onset age: $\leq 6 \mathrm{Y}$ (years old), 6-12 Y $(>6, \leq 12$ years old), and $12-18 \mathrm{Y}(>12,<18$ years old)

${ }^{\mathrm{b}}$ Recurrence was defined as disease flare-up after complete remission and medication free for at least three months

c CS dependence was defined as more than 6 weeks of daily oral CS intake

${ }^{d}$ Refractory disease was defined as not achieving complete remission 6 months after disease onset 


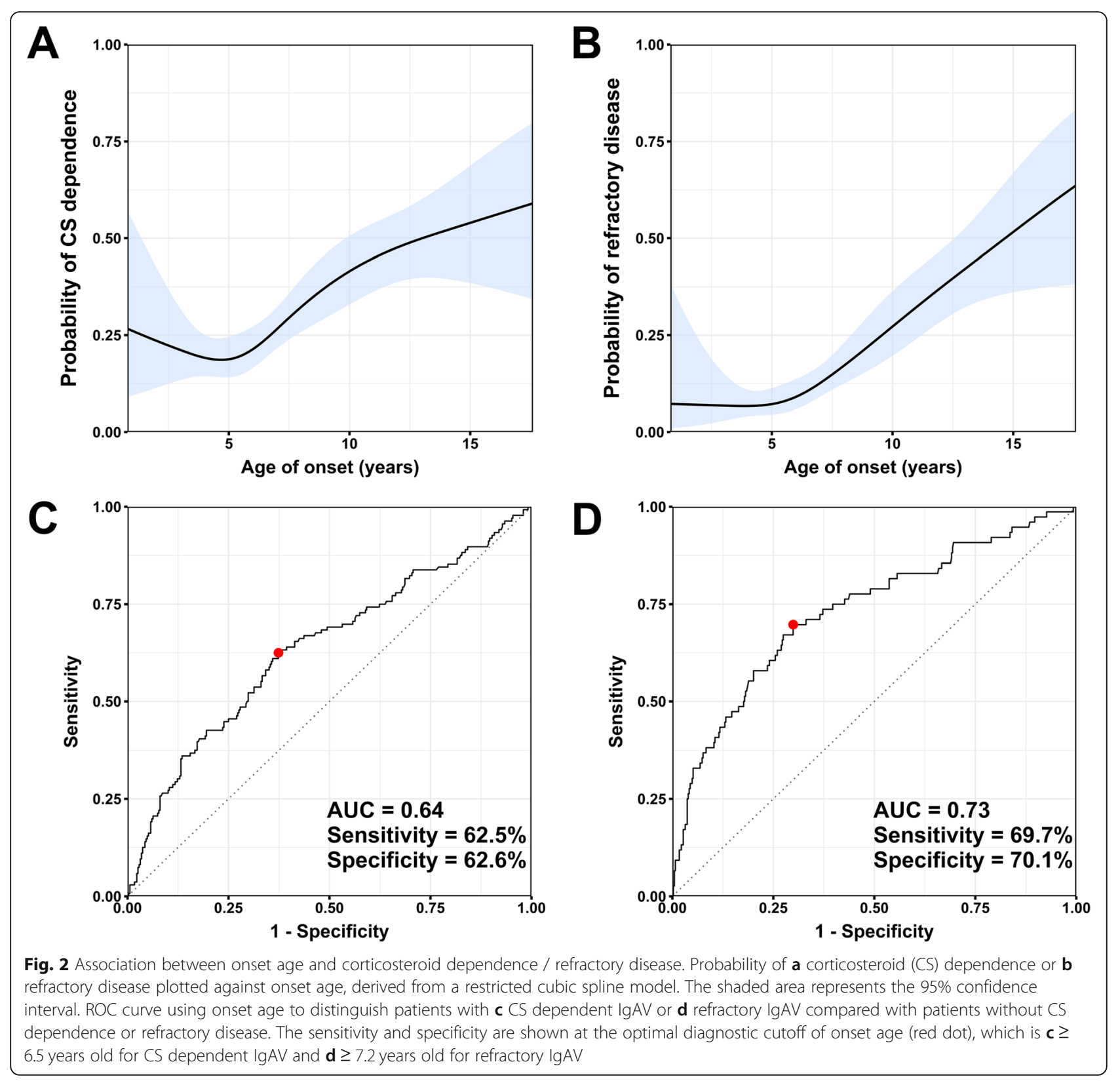

showed that pediatric patients over 10 years old stood a higher risk of renal involvement and severe renal disease $[21,22]$. However, our analysis demonstrated that the risk of renal involvement appeared to increase continuously with onset age (see Additional file 1: Fig. S1).

As onset age increased, not only clinical manifestations but also laboratory data differed. To adjust for the confounding effect of different normative values for the hemogram and IgA at different ages, we subjected agecorrected Z-scores to further analysis. The mean Zscores of WBC and IgA were positive in all three subgroups, indicating that the WBC count and IgA of patients with IgAV were higher than normal range irrespective of age, possibly reflecting the important roles of
WBC and IgA in the pathogenesis in IgAV. As onset age increased, the Z-score of WBC increased, but the Zscore of IgA decreased. Though the mechanism remains unclear, we hypothesized that the relative importance of WBC and IgA in pathogenesis of IgAV changes in patients of different onset age. The importance of WBC might increase as onset age increases, and could possibly contribute to the higher frequency of renal involvement and refractory disease in elder children, but further studies are warranted.

The disease course of pediatric IgAV is usually benign, but $14-66 \%$ patients experience recurrence [12, 23-26]. The variation in the reported recurrence rate could be related to the discrepant definitions of recurrence used 
in different studies. In our analysis, the overall recurrence rate was $9.5 \%$, which is lower compared to previous studies. It is possibly attributable to the relatively stringent definition of recurrence in our study design (reappearance of symptoms or signs 3 months after discontinuation of medications). For instance, a prospective study of 74 Greek children with IgAV reported the highest rate of recurrence $(66 \%)$ with a more lenient definition (reappearance of symptoms of signs after a 2-week asymptomatic period) [26]. Factors impacting the recurrence of IgAV in previous studies included older age (age $>8$ years old) and renal involvement [27]. In our study, only renal involvement was associated with a significantly higher risk of recurrence, while onset age showed only trend-level association.

With the self-limited nature of IgAV, most cases resolve within 4 weeks [28]. CS and/or DMARDs are usually considered in patients with severe visceral involvement, though there is a lack of randomized controlled trials demonstrating efficacy [29]. Treatment with CS might lessen the severity and duration of GI, joint, and cutaneous symptoms [28,30], but does not alter the disease course nor prevent renal involvement [27, 31, 32 ]. In the literature, around $19.8-73.2 \%$ patients required CS use [12, 33, 34], while $0-75.9 \%$ patients took DMARDs [12, 34]. The variation in the reported administration rate of CS and DMARDs could relate to differences in disease severity and clinical characteristics in different studies. The preferred treatment protocol for pediatric IgA vasculitis might also vary between different medical institutions. Administration rate of CS and DMARDs in our study were 83.9 and $53.2 \%$ respectively. CS administration rate was especially high, compared to previous studies. This could possibly be attributed to practice differences or referral bias. In our institution, as a tertiary referral center, often cares for patients with higher disease severity or those transferred from local hospitals due to recalcitrant disease course. These patients often required more aggressive treatment.

Most physicians avoid extended CS administration, due to adverse effects of long-term CS use, such as osteoporosis, weight gain, and growth retardation. Some patients still require long-term CS use and/or additional DMARDs because of persistent active disease status under CS or disease relapse during CS tapering. In our study, the overall rates of CS dependence and refractory disease were 28.1 and $15.7 \%$, respectively. Both increased with increasing onset age and were elevated in patents with renal involvement. Only a few previous studies addressed these issues. Alfredo et al. reported that $7.2 \%$ of IgAV patients had persistent active disease status for a period of 1 year or longer [25]. The total CS burden was highest in the 12-18 years old group, as measured by total CS dose or exposure days. To our knowledge, this has not been mentioned in previous literature.

In this study, the most commonly used DMARDs was azathioprine. Azathioprine, the most frequently prescribed, has been documented to achieve beneficial renal outcomes in alleviating histopathological change and shortening the clinical course of severe IgAV nephritis in combination with CS, though limited case numbers [35]. The major adverse effects of azathioprine include liver toxicity and bone marrow suppression. In our study, no patients developed liver enzyme abnormalities, but neutropenia and pancytopenia were observed. Regular monitoring of complete blood cell count and liver enzymes is indicated in patients under azathioprine.

Novel drugs with higher safety and efficacy in achieving CS sparing and preventing relapse are desired. Rituximab, a monoclonal antibody which depletes B cell by targeting CD20 [36], was reported to be beneficial for eight chronic steroid-dependent cases in reducing oral CS burden [37]. In our study, adjuvant rituximab treatment was administered in one case with persistent active disease status (arthritis and abdominal pain) despite CS and multiple DMARDs for 10 months. Partial remission was achieved after rituximab treatment.

There were several limitations in this cohort study. Given its retrospective nature, variable thoroughness of documentation might cause difficulties in distinguishing arthritis from focal angioedema around joints resulting from vasculitis. In younger children, an inability to express themselves could compound this problem. Further image studies, such as soft tissue sonography may help to differentiate these two conditions. A second limitation is the referral bias due to our institution's status as a tertiary referral hospital. Patients with higher disease severity may be overrepresented in our cohort, and our single center experience may not reflect the universal condition. Further confirmation of our findings by multicenter studies or nationwide databases are warranted. Finally, the possibility of false positive results could be increased due to multiple hypothesis testing.

This is the largest cohort study demonstrating that pediatric IgAV with different onset ages are associated with distinct clinical manifestations and outcomes (including total CS burden). We found that the probability of developing CS dependence, refractory disease, and renal involvement increased with onset age. This indicates that the course of pediatric IgAV is not as benign as previously thought, especially in adolescents. Early introduction of DMARDs or biological agents in IgAV patients with either CS dependence or refractory course might help reducing CS burden and adverse effects of long-term CS use. However, larger and preferably randomized controlled studies are still needed for further clarification. 


\section{Conclusion}

Pediatric IgAV with different onset ages are associated with distinct clinical manifestations and outcomes. The probability of developing corticosteroid dependence, refractory disease, and renal involvement increased with onset age.

Early introduction of DMARDs or biological agents in IgAV patients with either CS dependence or refractory course might help reducing CS burden and adverse effects of long-term CS use.

\section{Supplementary Information}

The online version contains supplementary material available at https://doi. org/10.1186/s12969-020-00480-3

\section{Additional file 1.}

\section{Abbreviations}

IgAV: Immunoglobulin A vasculitis; IgA: Immunoglobin A; IL-8: Interleukin-8; Gl: Gastrointestinal; CS: Corticosteroids; NSAIDs: Non-steroidal antiinflammatory drugs; DMARDs: Disease-modifying anti-rheumatic drugs; RBCs: Red blood cells; ROC: Receiver operating characteristic; Hb: Hemoglobin; PIt: Platelet; WBC: White blood cell; NLR: Neutrophil to lymphocyte ratio; PLR: Platelet to lymphocyte ratio; IQR: Interquartile range; AUC: Area under curve

\section{Acknowledgements}

We thank Dr. Paul-Chen Hsieh for his assistance with statistical analysis and graphical presentation

\section{Authors' contributions}

Chun-Hua Liao designed research, collected and analyzed data, performed statistical analysis, wrote paper, had primary responsibility for final content; Melody Tsai collected data; Yao-Hsu Yang conducted research, analyzed data; Bor-Luen Chiang conducted research, analyzed data; Li-Chieh Wang conducted research, analyzed data; All authors read and approved the final manuscript.

\section{Funding}

This research did not receive any specific grants from funding agencies in the public, commercial, or not-for-profit sectors.

\section{Availability of data and materials}

The datasets used in the study are available from the corresponding author on reasonable request.

\section{Ethics approval and consent to participate}

The Ethics Committee of National Taiwan University Hospital approved the study. (201608095RIND).

\section{Consent for publication}

Not applicable.

\section{Competing interests}

The authors declare that they have no conflict of interests.

\section{Author details}

'Department of Pediatrics, National Taiwan University Hospital, No.8, Chung Shan South Road, Taipei 10002, Taiwan. ${ }^{2}$ Department of Medical Research, National Taiwan University Hospital, Taipei, Taiwan.
Received: 8 March 2020 Accepted: 1 November 2020

Published online: 10 November 2020

\section{References}

1. Gardner-Medwin JM, Dolezalova P, Cummins C, Southwood TR. Incidence of Henoch-Schonlein purpura, Kawasaki disease, and rare vasculitides in children of different ethnic origins. Lancet. 2002;360(9341):1197-202.

2. Piram M, Maldini C, Biscardi S, De Suremain N, Orzechowski C, Georget E, et al. Incidence of IgA vasculitis in children estimated by four-source capture-recapture analysis: a population-based study. Rheumatology. 2017; 56(8):1358-66.

3. Yang YH, Hung CF, Hsu CR, Wang LC, Chuang YH, Lin YT, et al. A nationwide survey on epidemiological characteristics of childhood HenochSchonlein purpura in Taiwan. Rheumatology. 2005;44(5):618-22.

4. Yang YH, Chuang YH, Wang LC, Huang HY, Gershwin ME, Chiang BL. The immunobiology of Henoch-Schonlein purpura. Autoimmun Rev. 2008;7(3): 179-84.

5. Yang YH, Lai HJ, Huang CM, Wang LC, Lin YT, Chiang BL. Sera from children with active Henoch-Schonlein purpura can enhance the production of interleukin 8 by human umbilical venous endothelial cells. Ann Rheum Dis. 2004;63(11):1511-3.

6. Heineke $\mathrm{MH}$, Ballering $\mathrm{AV}$, Jamin $\mathrm{A}$, Ben Mkaddem S, Monteiro RC, Van Egmond $\mathrm{M}$. New insights in the pathogenesis of immunoglobulin a vasculitis (Henoch-Schonlein purpura). Autoimmun Rev. 2017;16(12):124653

7. Watts RA, Lane S, Scott DG. What is known about the epidemiology of the vasculitides? Best Pract Res Clin Rheumatol. 2005;19(2):191-207.

8. Garcia-Porrua C, Calvino MC, Llorca J, Couselo JM, Gonzalez-Gay MA. Henoch-Schonlein purpura in children and adults: clinical differences in a defined population. Semin Arthritis Rheum. 2002;32(3):149-56.

9. Audemard-Verger A, Terrier B, Dechartres A, Chanal J, Amoura Z, Le Gouellec N, et al. Characteristics and Management of IgA Vasculitis (Henoch-Schonlein) in Adults: Data From 260 Patients Included in a French Multicenter Retrospective Survey. Arthritis Rheumatol. 2017;69(9):1862-70.

10. Hung SP, Yang YH, Lin YT, Wang LC, Lee JH, Chiang BL. Clinical manifestations and outcomes of Henoch-Schonlein purpura: comparison between adults and children. Pediatr Neonatol. 2009:50(4):162-8.

11. Pillebout E, Thervet E, Hill G, Alberti C, Vanhille P, Nochy D. HenochSchonlein Purpura in adults: outcome and prognostic factors. J Am Soc Nephrol. 2002;13(5):1271-8.

12. Blanco R, Martinez-Taboada VM, Rodriguez-Valverde V, Garcia-Fuentes M, Gonzalez-Gay MA. Henoch-Schonlein purpura in adulthood and childhood: two different expressions of the same syndrome. Arthritis Rheum. 1997; 40(5):859-64.

13. Tracy A, Subramanian A, Adderley NJ, Cockwell P, Ferro C, Ball S, et al. Cardiovascular, thromboembolic and renal outcomes in $\lg A$ vasculitis (Henoch-Schonlein purpura): a retrospective cohort study using routinely collected primary care data. Ann Rheum Dis. 2019;78(2):261-9.

14. Ozen S, Pistorio A, lusan SM, Bakkaloglu A, Herlin T, Brik R, et al. EULAR/ PRINTO/PRES criteria for Henoch-Schönlein purpura, childhood polyarteritis nodosa, childhood Wegener granulomatosis and childhood Takayasu arteritis: Ankara 2008. Part II: final classification criteria. Ann Rheum Dis. 2010; 69(5):798-806

15. Harrell FE Jr, Lee KL, Pollock BG. Regression models in clinical studies: determining relationships between predictors and response. J Natl Cancer Inst. 1988;80(15):1198-202.

16. Lanzkowsky P, Lipton JM, Fish JD. Lanzkowsky's manual of pediatric hematology and oncology: academic press; 2016.

17. Stiehm ER, Fudenberg HH. Serum levels of immune globulins in health and disease: a survey. Pediatrics. 1966;37(5):715-27.

18. De Ciuceis C, Rossini C, La Boria E, Porteri E, Petroboni B, Gavazzi A, et al, Immune mechanisms in hypertension. High Blood Pressure Cardiovasc Prev. 2014;21(4):227-34

19. Chang W-L, Yang Y-H, Lin Y-T, Chiang B-L. Gastrointestinal manifestations in Henoch-Schönlein purpura: a review of 261 patients. Acta Paediatr. 2004; 93(11):1427-31.

20. Rhim JW, Lee YT, Kang HM, Suh JS, Lee KY. Changes in clinical features in Henoch-Schonlein purpura during three decades: an observational study at a single hospital in Korea. Clin Rheumatol. 2019;38(10):2811-8. 
21. Chan H, Tang YL, Lv XH, Zhang GF, Wang M, Yang HP, et al. Risk factors associated with renal involvement in childhood Henoch-Schonlein Purpura: a meta-analysis. PLoS One. 2016;11(11):e0167346.

22. Shin Jl, Park JM, Shin YH, Hwang DH, Kim JH, Lee JS. Predictive factors for nephritis, relapse, and significant proteinuria in childhood HenochSchonlein purpura. Scand J Rheumatol. 2006;35(1):56-60.

23. Trapani S, Micheli A, Grisolia F, Resti M, Chiappini E, Falcini F, et al. Henoch Schonlein purpura in childhood: epidemiological and clinical analysis of 150 cases over a 5-year period and review of literature. Semin Arthritis Rheum. 2005;35(3):143-53.

24. Calvo-Rio V, Hernandez JL, Ortiz-Sanjuan F, Loricera J, Palmou-Fontana N, Gonzalez-Vela MC, et al. Relapses in patients with Henoch-Schonlein purpura: analysis of 417 patients from a single center. Medicine. 2016;95(28): e4217.

25. Alfredo CS, Nunes NA, Len CA, Barbosa CM, Terreri MT, Hilario MO. HenochSchonlein purpura: recurrence and chronicity. J Pediatr. 2007;83(2):177-80.

26. Fretzayas A, Sionti I, Moustaki M, Papadimitriou A, Nicolaidou P. HenochSchonlein purpura: a long-term prospective study in Greek children. J Clin Rheumat. 2008;14(6):324-31.

27. Jauhola O, Ronkainen J, Koskimies O, Ala-Houhala M, Arikoski P, Holtta T, et al. Clinical course of extrarenal symptoms in Henoch-Schonlein purpura: a 6-month prospective study. Arch Dis Child. 2010;95(11):871-6.

28. Saulsbury FT. Henoch-Schonlein purpura in children. Report of 100 patients and review of the literature. Medicine. 1999;78(6):395-409.

29. Ozen S, Marks SD, Brogan P, Groot N, de Graeff N, Avcin T, et al. European consensus-based recommendations for diagnosis and treatment of immunoglobulin A vasculitis-the SHARE initiative. Rheumatol. 2019;58(9): 1607-16.

30. Weiss PF, Klink AJ, Localio R, Hall M, Hexem K, Burnham JM, et al. Corticosteroids may improve clinical outcomes during hospitalization for Henoch-Schonlein purpura. Pediatrics. 2010;126(4):674-81.

31. Jauhola O, Ronkainen J, Koskimies O, Ala-Houhala M, Arikoski P, Holtta T, et al. Outcome of Henoch-Schonlein purpura 8 years after treatment with a placebo or prednisone at disease onset. Pediatr Nephrol. 2012;27(6):933-9.

32. Ronkainen J, Koskimies O, Ala-Houhala M, Antikainen M, Merenmies J, Rajantie J, et al. Early prednisone therapy in Henoch-Schonlein purpura: a randomized, double-blind, placebo-controlled trial. J Pediatr. 2006;149(2): $241-7$.

33. Lei WT, Tsai PL, Chu SH, Kao YH, Lin CY, Fang LC, et al. Incidence and risk factors for recurrent Henoch-Schonlein purpura in children from a 16-year nationwide database. Pediatr Rheumatol Online J. 2018;16(1):25.

34. Selewski DT, Ambruzs JM, Appel GB, Bomback AS, Matar RB, Cai Y, et al. Clinical characteristics and treatment patterns of children and adults with IgA nephropathy or IgA Vasculitis: findings from the CureGN study. Kidney Int Rep. 2018;3(6):1373-84.

35. Shin Jl, Park JM, Shin YH, Kim JH, Lee JS, Kim PK, et al. Can azathioprine and steroids alter the progression of severe Henoch-Schonlein nephritis in children? Pediatr Nephrol. 2005;20(8):1087-92.

36. Reff ME, Carner K, Chambers KS, Chinn PC, Leonard JE, Raab R, et al. Depletion of $\mathrm{B}$ cells in vivo by a chimeric mouse human monoclonal antibody to CD20. Blood. 1994;83(2):435-45.

37. Crayne CB, Eloseily E, Mannion ML, Azerf SP, Weiser P, Beukelman T, et al. Rituximab treatment for chronic steroid-dependent Henoch-Schonlein purpura: 8 cases and a review of the literature. Pediatr Rheumatol Online J. 2018:16(1):71.

\section{Publisher's Note}

Springer Nature remains neutral with regard to jurisdictional claims in published maps and institutional affiliations.

Ready to submit your research? Choose BMC and benefit from:

- fast, convenient online submission

- thorough peer review by experienced researchers in your field

- rapid publication on acceptance

- support for research data, including large and complex data types

- gold Open Access which fosters wider collaboration and increased citations

- maximum visibility for your research: over $100 \mathrm{M}$ website views per year

At $\mathrm{BMC}$, research is always in progress.

Learn more biomedcentral.com/submissions 